\title{
Correspondence
}

\section{Trainees in the specialities}

Sir: Approaching the end of my senior registrar training in Old Age Psychiatry I found John Sandford's letter (Psychiatric Bulletin, February 1997, 21, 120) particularly apposite.

I have obtained utterly conflicting advice from senior members of the College regarding the value of dual accreditation in Old Age and General Psychiatry. I am thus in the position of having an acceptable training in Old Age Psychiatry, but the Section of OAP has now moved the goalposts and recommended that senior/specialist registrars obtain dual accreditation and consequently extend their training. It is very frustrating to see senior trainees in General Psychiatry taking up consultant posts after only three years in the grade while those of us in the specialities ponder the risks of being singly accredited consultants. Surely we are all psychiatrists and so why cannot we all aim for a CCST in psychiatry and then allow our curriculum vitae to indicate any special interests? Currently chaos reigns and consultant recruitment in the specialities is suffering. The Section of OAP is now recommending that Trusts look to the US for consultant staff. Are Americans better trained than home-grown psychiatrists? The situation would be laughable were it not so tragic for the future of British psychiatry.

\section{SIMON THACKER}

Department of Health Care of the Elderly. Medical School, Nottingham University Hospital, NG7 2UH

Sir: I can understand Dr Thacker's confusion. I am afraid it has been a confusing situation for all of us. The issue was discussed again at the Joint Committee for Higher Psychiatric Training (JCHPT) on 26 March and my understanding of the current situation is that a Certificate of Completion of Specialist Training (CCST) is necessary to practise as a consultant, but that obtaining a CCST in General Psychiatry does not imply the inability to practise in Old Age Psychiatry or vice versa. Presumably the College representative on the Appointments Committee would take into account details of the curriculum vitae as well as in what area a CCST had been granted. My understanding is that CCSTs are permissive rather than restrictive. However, I can understand anybody currently in training deciding to go for a dual CCST because none of us can be certain how the situation will evolve in the future. A number of established consultants in
Old Age Psychiatry have argued successfully that they should be on the Specialist Register as both General and Old Age Psychiatrists, which reflects concern over similar issues but does not imply, as in Dr Thacker's case, the need for an extra year in training. I am not happy with the Old Age Section being cast as the villain. Like JCHPT and other College bodies, we are doing our best to interpret an evolving situation which we do not control. Finally, I should stress that the Old Age Section is not particularly recommending that Trusts look to the US for consultant staff. This recommendation was one of the Department of Health's solutions to the current manpower crisis and was merely reported through the Old Age Section. As a matter of policy the Old Age Section would prefer training of Specialist Registrars within the UK to meet our own needs for consultant appointments.

J. P. WATtis, Chairman of the Section for Psychiatry and Old Age

\section{Disulfiram implantation}

Sir: Shergill et al (Psychiatric Bulletin. October $1996,20,624)$ report beneficial outcome in six of twelve patients treated with disulfiram implantation and mention our similar findings (Malcolm \& Madden, 1973). They do not, regrettably, mention our second paper (Malcolm et al, 1974) which confirmed our initial impression that implants were pharmacologically inactive. Our implants produced minimal and short-lasting levels of blood disulfiram and of metabolite in exhaled breath, as compared with oral use. The implant dose, which is alleged to last for six months, is miniscule in comparison with the total oral dosage over the same period. We saw no true reactions to alcohol in our implanted patients. Shergill and colleagues did not attempt a 'challenge' with alcohol. We note that a third of their patients drank, seemingly with no reaction. Most of their patients requested the implant, a situation we encountered, which shows patients' high expectations, even suggestibility - patients know what a reaction should be and their subsequent experiences are psychogenic or the misinterpreted effects of alcohol.

It is reported (van der Lann, 1992) that 50000 alcoholics at one Russian clinic have received the traditional 'Esperal' implants or the intravenous 'torpedo' of disulfiram; although no deaths have resulted, many are convinced that they will die if 